\title{
Long-Term Survival in Patients With Tracheostomy and Prolonged Mechanical Ventilation in Olmsted County, Minnesota
}

\author{
Marija Kojicic MD, Guangxi Li MD, Adil Ahmed MBBS, Lokendra Thakur MBBS, \\ Cesar Trillo-Alvarez MD, Rodrigo Cartin-Ceba MD, Peter C Gay MD, and Ognjen Gajic MD MSc
}

\begin{abstract}
BACKGROUND: An increasing number of patients require prolonged mechanical ventilation (PMV), which is associated with high morbidity and poor long-term survival, but there are few data regarding the incidence and outcome of PMV patients from a community perspective. METHODS: We retrospectively reviewed the electronic medical records of adult Olmsted county, Minnesota, residents admitted to the intensive care units at the 2 Mayo Clinic Rochester hospitals from January 1, 2003, to December 31, 2007, who underwent tracheostomy for PMV. RESULTS: Sixtyfive patients, median age 68 years (interquartile range [IQR] 49-80 y), 39 male, underwent tracheostomy for PMV, resulting in an age-adjusted incidence of 13 (95\% CI 10-17) per 100,000 patient-years at risk. The median number of days on mechanical ventilation was 24 days (IQR 1837 d). Forty-six patients $(71 \%)$ survived to hospital discharge, and $36(55 \%)$ were alive at 1-year follow-up. After adjusting for age and baseline severity of illness, the presence of COPD was independently associated with 1-year mortality (hazard ratio 3.4, 95\% CI 1.4-8.2\%). CONCLUSIONS: There was a considerable incidence of tracheostomy for PMV. The presence of COPD was an independent predictor of 1-year mortality. Key words: mechanical ventilation; tracheostomy; COPD; survival. [Respir Care 2011;56(11):1765-1770. (C) 2011 Daedalus Enterprises]
\end{abstract}

\section{Introduction}

An increasing number of patients require mechanical ventilation, for various reasons, and there has been a pro-

\footnotetext{
The authors are affiliated with the Division of Pulmonary and Critical Care Medicine, Department of Internal Medicine, Mayo Clinic College of Medicine, Rochester, Minnesota. Dr Kojicic is also affiliated with the Institute for Pulmonary Diseases of Vojvodina, Sremska Kamenica, Serbia. $\mathrm{Dr} \mathrm{Li}$ is also affiliated with the Department of Pulmonary Medicine, Guang An Men Hospital, China Academy of Chinese Medical Science, Beijing, China.
}

This research was partly supported by National Institutes of Health grant HL78743-01A1.

\footnotetext{
Dr Kojicic presented a version of this paper at the 105th International Conference of the American Thoracic Society, held May 15-20, 2009, in San Diego, California.
}

Correspondence: Ognjen Gajic MD MSc, Division of Pulmonary and Critical Care Medicine, Mayo Clinic, 200 First Street SW, Rochester MN 55905. E-mail: gajic.ognjen@ mayo.edu.

DOI: $10.4187 /$ respcare.01096 portional increase in patients also needing prolonged mechanical ventilation (PMV). PMV accounts for about $10 \%$ of all mechanically ventilated patients. ${ }^{1,2}$ Although these patients represent a smaller proportion of intensive care unit (ICU) patients, they consume substantial ICU resources. ${ }^{3}$ Studies from referral centers have found poor long-term survival among PMV patients, with 1-year mortality of $56-71 \% .^{1,4-7}$ Of those who are transferred to longterm care hospitals $52 \%$ die within the first year of

See the Related Editorial on Page 1859

follow-up. ${ }^{8}$ Considering the high morbidity, mortality, and cost of PMV,, 10 there is an increasing interest in identifying PMV patients who are at higher risk of death. Data from a community-based perspective could help limit the referral bias inherent in the epidemiologic studies from critical-care sources. ${ }^{11}$

The purpose of this study was to determine the incidence and the contemporary prognosis associated with PMV in Olmsted county, Minnesota. We took advantage of the fact that virtually all healthcare in Olmsted county 


\section{Long-Term Survival in Patients With Tracheostomy and Prolonged Ventilation}

is provided by just 2 providers, and only the Mayo Clinic offers critical-care services. With data from Olmsted county we can conduct detailed studies of etiology and outcome of critical illness in a defined geographic population with unrestricted access to mechanical ventilation, including PMV.

\section{Methods}

The Mayo Clinic institutional review board approved the study protocol and waived the informed-consent requirement. As required by Minnesota law, we excluded patients who had previously denied authorization for the use of their medical records for research. This was a retrospective cohort study, performed at Mayo Clinic, Rochester, Minnesota. We reviewed electronic medical records from residents of Olmsted county, $\geq 18$ years of age, admitted to ICUs at the 2 Mayo Clinic Rochester hospitals from January 1, 2003, to December 31, 2007 who underwent tracheostomy for anticipated or established PMV and/ or who had failed multiple ventilator-weaning attempts. ${ }^{12}$

According to the 2000 United States census, the population of Olmsted county was 124,277, 50.9\% female, $90.3 \%$ white, and $10.7 \%$ age $\geq 65$ years. The patients were admitted to one of the 8 adult Mayo Clinic ICUs, which include medical, surgical, and cardiac care units, with a total of 154 beds. Olmsted county age-groupspecific ICU admission and utilization rates were previously reported. ${ }^{13}$ Olmsted county residents were identified via their home zip codes at ICU admission.

Patients who underwent tracheostomy were identified according to the International Classification of Diseases, 9th Revision, Clinical Modification (ICD-9 CM, code 31.1 temporary tracheostomy). We reviewed the electronic medical records to confirm the indication for temporary tracheostomy (respiratory failure with anticipated or PMV) and to collect data on demographics, comorbidities, and clinical and laboratory variables that could be related to long-term prognosis. The incidence of tracheostomy for PMV was age-adjusted according to the 2000 United States standard population. ${ }^{14}$ Mortality was assessed by reviewing the medical records and the Olmsted county electronic death certificates.

We measured severity of illness with the Acute Physiology and Chronic Health Evaluation (APACHE) III at ICU admission. ${ }^{15}$ We used standard clinical definitions to define comorbidities: COPD, ${ }^{16}$ diabetes mellitus, ${ }^{17}$ trauma, ${ }^{18}$ neuromuscular disease (acute or chronic), ${ }^{19}$ major surgery, ${ }^{20}$ and cumulative Charlson score. ${ }^{21}$

We also used standard definitions to determine the presence or absence of ICU complications, including acute lung injury ${ }^{22}$ and shock. ${ }^{23}$ If a patient had multiple tracheostomies, only the data from the first admission were used for statistical analysis.

\section{Statistical Analysis}

Continuous data are expressed as median and interquartile range (IQR). Categorical variables are expressed as counts and percentages. We compared the characteristics of patients who survived more than 1 year versus less than 1 year with the Wilcoxon rank-sum test, chi-square test, or Fisher's exact test, as appropriate. We calculated the total number of days on mechanical ventilation from the initiation of mechanical ventilation until the patient was weaned, but excluded patients who were continued on mechanical ventilation following hospital discharge. We used survival analysis methods to assess time-to-event data, and calculated 1-year survival from the initiation of mechanical ventilation. We used Cox proportional regression to identify predictors of survival. Pertinent variables were selected based on both clinical and statistical variables or according to previous epidemiologic studies, clinical judgment, and missing data. Variables that were associated with adverse 1 -year outcome in univariate analysis $(P<.1)$ were considered for multivariate Cox proportional regression model analysis. Statistical significance was set at $P=.05$ for all hypotheses. Statistical analyses were performed with statistics software (JMP 7, SAS Institute, Cary, North Carolina).

\section{Results}

Six-hundred ninety-two Olmsted county residents received invasive mechanical ventilation $(\geq 12 \mathrm{~h})$ during the study period. One-hundred eighteen patients had the ICD 9 code for temporary tracheostomy. The 52 patients who received tracheostomy for head and neck carcinoma or airway protection were excluded.

Sixty-five patients, 39 male, median age 68 years (IQR 49-80 y), underwent tracheostomy for PMV, resulting in an age-adjusted incidence of approximately 13 (95\% CI 10-17) per 100,000 person-years at risk for the population of Olmsted county. One patient had tracheostomy performed twice for the purpose of PMV during the study period. Fifty-one (77\%) of the tracheostomies were surgical. The median number of days on mechanical ventilation was 24 days (IQR 18-37 d) and the median time from initiation of mechanical ventilation to tracheostomy was 10 days (IQR 7-14 d). Forty-six patients (71\%) survived to hospital discharge, and $36(55 \%)$ were alive at 1-year follow-up. Survival was similar in patients who were ventilated for more than versus less than 21 days (16/26 vs $20 / 39, P=.19$ via log-rank test). Only 3 survivors did not have a subsequent follow-up visit after 1 year, and their vital status was ascertained from the Olmsted county electronic death certificates. Table 1 describes the survivors and non-survivors. 


\section{Long-Term Survival in Patients With Tracheostomy and Prolonged Ventilation}

Table 1. Survivors Versus Non-survivors at One Year

\begin{tabular}{|c|c|c|c|}
\hline & $\begin{array}{l}\text { Non-survivors } \\
\quad(n=29)\end{array}$ & $\begin{array}{l}\text { Survivors } \\
(n=36)\end{array}$ & $P$ \\
\hline \multicolumn{4}{|l|}{ Demographic Characteristics } \\
\hline Age, median (IQR), y & $76(68-82)$ & $57(33-68)$ & $<.001$ \\
\hline Male, no. $(\%)$ & $16(55)$ & $23(64)$ & .60 \\
\hline White, no. (\%) & $25(86)$ & $27(75)$ & .35 \\
\hline History of tobacco smoking, no. (\%) & $18(62)$ & $19(53)$ & 62 \\
\hline History of alcohol abuse, no. (\%) & $2(7)$ & $5(14)$ & .45 \\
\hline Body mass index, median (IQR), $\mathrm{kg} / \mathrm{m}^{2}$ & $25(22-31)$ & $26(22-30)$ & 67 \\
\hline \multicolumn{4}{|l|}{ Comorbidities } \\
\hline Charlson score, median (IQR) & $3(2-4)$ & $2(0-3)$ & .13 \\
\hline COPD, no. $(\%)$ & $11(38)$ & $2(6)$ & .002 \\
\hline Trauma, no. $(\%)$ & $1(3)$ & $8(22)$ & .04 \\
\hline Neuromuscular disease, no. (\%) & $2(7)$ & $5(14)$ & .44 \\
\hline Major surgery, no. (\%) & $11(38)$ & $11(31)$ & .61 \\
\hline Congestive heart failure, no. $(\%)$ & $7(24)$ & $8(22)$ & .56 \\
\hline Ejection fraction $<45 \%$, no. $(\%)^{*}$ & $4(17)$ & $4(13)$ & $>.99$ \\
\hline Dialysis, no. $(\%)$ & $7(24)$ & $5(14)$ & .35 \\
\hline Diabetes mellitus, no. (\%) & $11(38)$ & $7(19)$ & .16 \\
\hline \multicolumn{4}{|l|}{ ICU Admission Characteristics } \\
\hline ICU Admission source, no. (\%) & & & .74 \\
\hline Direct admission & $1(4)$ & $0(0)$ & \\
\hline Emergency room & $9(31)$ & $11(31)$ & \\
\hline Floor & $9(31)$ & $9(25)$ & \\
\hline Operating room & $9(31)$ & $15(42)$ & \\
\hline Other hospital & $1(4)$ & $1(3)$ & \\
\hline APACHE III score, median (IQR) & $81(63-92)$ & $64(51-91)$ & .14 \\
\hline APACHE III hospital predicted mortality, median (IQR) & $0.38(0.17-0.93)$ & $0.23(0.08-0.43)$ & .06 \\
\hline \multicolumn{4}{|l|}{ ICU treatments and complications } \\
\hline Acute lung injury, no. $(\%) \dagger$ & $20(69)$ & $20(56)$ & .31 \\
\hline Shock, no. $(\%) \dagger$ & $18(62)$ & $23(64)$ & $>.99$ \\
\hline Platelet count $\leq 150 \times 10^{9} / \mathrm{L} \ddagger$ & $25(86)$ & $23(68)$ & .14 \\
\hline Do-not-resuscitate status at hospital admission, no. (\%) & $2(6.9)$ & $3(8.3)$ & $>.99$ \\
\hline \multicolumn{4}{|l|}{ Outcomes } \\
\hline 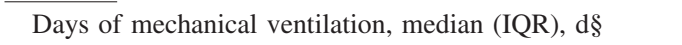 & $24(18-34)$ & $24(17-40)$ & .94 \\
\hline Hospital stay, median (IQR), d & $42(25-83)$ & $43(30-61)$ & .86 \\
\hline Hospital Disposition, no. (\%) & $(n=10)$ & $(n=36)$ & .06 \\
\hline Home & $1(10)$ & $11(31)$ & \\
\hline Other Hospital & $0(0)$ & $3(8)$ & \\
\hline Nursing Home & $7(70)$ & $9(25)$ & \\
\hline Rehabilitation & $2(20)$ & $13(36)$ & \\
\hline \multicolumn{4}{|l|}{$\begin{array}{l}\text { * Echocardiograph data were available from } 54 \text { patients. } \\
\dagger \text { At any time during intensive care unit (ICU) stay. } \\
\ddagger \text { Lowest value during ICU stay. } \\
\text { Patients who were continued on mechanical ventilation were excluded from analysis. } \\
\text { APACHE = Acute Physiology and Chronic Health Evaluation }\end{array}$} \\
\hline
\end{tabular}

Five patients, including 4 with neuromuscular diseases, were continued on mechanical ventilation after hospital discharge, and 4 of them survived 1 year. None of those patients was liberated from mechanical ventilation during 1-year follow-up. Nineteen patients (29\%) died in hospital (median hospital stay 34 d, IQR 24-77 d), 16 (84\%) of them met the diagnostic criteria for acute lung injury. Of the 10 patients who died after hospital discharge, 4 had a cerebrovascular event and 3 developed new respiratory failure (Table 2). Median survival after hospital discharge in those 10 patients was 48 days (IQR 28-73 d).

After adjusting for APACHE III hospital predicted mortality in a Cox proportional hazard analysis, both age (hazard ratio [HR] 1.7, 95\% CI 1.3-2.4) and the presence of COPD were independently associated with lower 1-year survival (hazard ratio 3.4, 95\% CI 1.4-8.2) (Table 3 and 


\section{Long-Term Survival in Patients With Tracheostomy and Prolonged Ventilation}

Table 2. Causes of Death After Hospital Discharge

\begin{tabular}{|c|c|c|c|c|}
\hline $\begin{array}{l}\text { Patient } \\
\text { Number }\end{array}$ & $\begin{array}{l}\text { Age } \\
(\mathrm{y})\end{array}$ & COPD & $\begin{array}{l}\text { Cause of Death Per Medical } \\
\text { Record or Death Certificate }\end{array}$ & $\begin{array}{l}\text { Days of } \\
\text { Survival } \\
\text { After } \\
\text { Discharge }\end{array}$ \\
\hline $1^{*}$ & 85 & No & $\begin{array}{l}\text { Respiratory failure (hypercapnic, } \\
\text { hypoxic respiratory failure, } \\
\text { diaphragmatic weakness) }\end{array}$ & 28 \\
\hline 2 & 87 & No & Gastric carcinoma & 31 \\
\hline 3 & 76 & No & Stroke (cerebral infarct) & 29 \\
\hline 4 & 41 & No & $\begin{array}{l}\text { Stroke (acute right cerebellar } \\
\text { hemorrhage) }\end{array}$ & 70 \\
\hline 5 & 77 & Yes & Stroke (not specified) & 46 \\
\hline 6 & 88 & No & Unknown & 80 \\
\hline 7 & 81 & Yes & Unknown & 23 \\
\hline 8 & 74 & Yes & $\begin{array}{l}\text { Respiratory failure (COPD, } \\
\text { squamous-cell lung cancer, } \\
\text { and stroke) }\end{array}$ & 58 \\
\hline 9 & 52 & Yes & $\begin{array}{l}\text { Respiratory failure (sepsis, acute } \\
\text { respiratory distress syndrome) }\end{array}$ & 84 \\
\hline 10 & 68 & No & $\begin{array}{l}\text { Necrotizing pancreatitis } \\
\text { (massive bleeding) }\end{array}$ & 49 \\
\hline
\end{tabular}

Table 3. Factors Associated With One-Year Survival

\begin{tabular}{lccccr}
\hline \hline & \multicolumn{4}{c}{ Hazard Ratio and 95\% CI } \\
\cline { 2 - 5 } & $\begin{array}{c}\text { Univariate } \\
\text { Analysis }\end{array}$ & $P$ & $\begin{array}{c}\text { Multivariate } \\
\text { Analysis* }\end{array}$ & $P$ \\
\hline Age per 10-y increase & $1.5(1.2-2.0)$ & $<.001$ & $1.7(1.3-2.4)$ & $<.001$ \\
$\begin{array}{l}\text { APACHE III hospital } \\
\text { predicted mortality }\end{array}$ & $1.2(1.03-1.4)$ & .02 & $1.25(1.06-1.46)$ & .007 \\
$\begin{array}{l}\text { per 10-unit increase } \\
\text { COPD }\end{array}$ & $3.1(1.4-6.6)$ & .008 & $3.4(1.4-8.2)$ & .009
\end{tabular}

* The model included age, Acute Physiology and Chronic Health Evaluation (APACHE III), hospital predicted mortality, and COPD. All patients were censored at one year.

Fig. 1). Of the 13 patients with COPD, pulmonary function test results were available from 11 (mean percent-of-predicted $\mathrm{FEV}_{1} 48 \%$, range $17-64 \%$ ). Two patients had very severe, 5 had severe, and 4 had moderate COPD, according to the Global Initiative for Chronic Obstructive Lung Disease ${ }^{16}$ criteria. The presence of comorbidities (chronic heart failure, diabetes, or hemodialysis) did not influence the long-term outcome.

\section{Discussion}

There was a considerable incidence of tracheostomy for PMV in Olmsted county, Minnesota. In addition to age, underlying COPD was associated with worse long-term survival. The 1-year mortality rate was lower than most

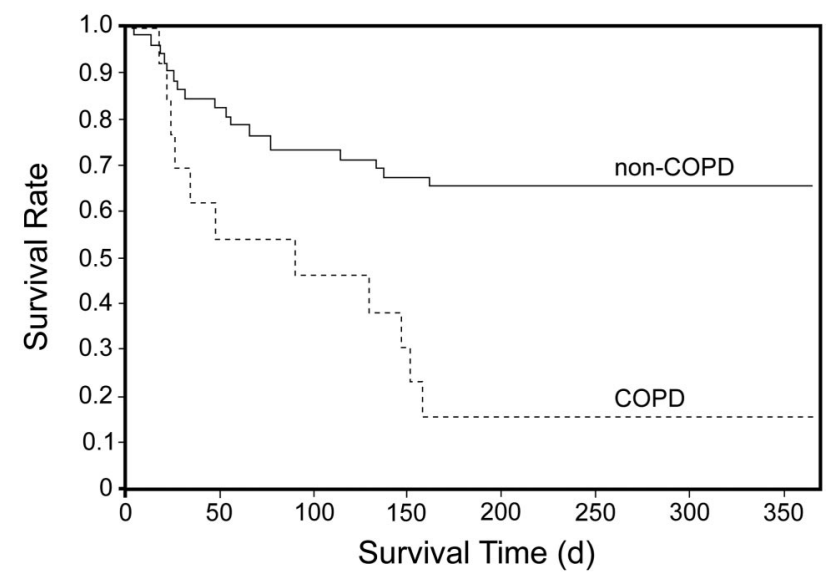

Fig. 1. Kaplan-Meier curve of 1-year survival in patients with versus without COPD, who required prolonged mechanical ventilation $(P=.006$ via log-rank test).

previous reports ${ }^{5,24-26}$ but similar to recent studies ${ }^{27,28}$ that included outside referral populations. Potential explanations include contemporary improvements in clinical practice, the availability of medical care for the population of Olmsted county, and the exclusion of referral bias. One of the limitations in comparing the long-term outcomes reported in different studies is a lack of a uniform definition of PMV, which has ranged from $\geq 4$ days to $>21$ days. Some studies 2,3 used tracheostomy placement to identify PMV patients, but those patients might not reach the chronic phase of critical illness (defined as the presence of mechanical ventilation on day 21). ${ }^{29}$ We believe that this is unlikely to have a confounding effect on our data, since outcomes were similar in our patients who were ventilated $<21$ days versus $>21$ days.

The majority of non-survivors died before hospital discharge. Among hospital survivors, those with unfavorable outcome died within the first 3 months after hospital discharge. The 6-month survival did not differ from 1-year survival (see Fig. 1). Patients with neuromuscular diseases, although they more likely to continue mechanical ventilation after hospital discharge (4 of 7 patients), had a relatively low mortality, consistent with a previous study. ${ }^{30} \mathrm{In}$ contrast, a large prospective study of patients discharged from a respiratory unit after PMV found a high mortality rate in patients who were not weaned from the ventilator, and neurological comorbidity was an independent predictor of weaning success. ${ }^{31}$

Similar to other studies, ${ }^{4,5,24,28,32}$ age was a significant predictor of 1-year survival, but, in contrast to those reports, COPD was also an independent predictor of 1-year mortality. This is not surprising, since both the in-hospital and 1-year mortality in patients with COPD who require mechanical ventilation is substantial. ${ }^{33}$ COPD is an independent predictor for duration of mechanical ventilation, and $60 \%$ of COPD patients in a recent study experienced 


\section{Long-Term Survival in Patients With Tracheostomy and Prolonged Ventilation}

weaning failure. ${ }^{34} \mathrm{COPD}$ was the most frequent premorbid respiratory diagnosis in ventilator-dependent patients referred to long-term care hospitals. ${ }^{35}$ COPD was also found to be an independent risk factor for long-term mortality in patients admitted to a specialized weaning center, but the analysis was restricted to hospital survivors. ${ }^{36}$ Other data on patients treated at home with tracheostomy and intermittent positive-pressure ventilation also reported COPD to be independently associated with mortality. ${ }^{37}$ Pilcher et al observed a higher post-discharge long-term mortality rate in COPD patients, compared to neuromuscular and surgical patients, but the difference was nonsignificant in multivariate analysis. ${ }^{30}$ The differences regarding predictive value of COPD on long-term survival of PMV patients could be due to the fact that patients with COPD are not always offered, or choose not to undergo, invasive mechanical ventilation because of poor prognosis. ${ }^{38}$ In addition, unlike studies that found no association between COPD and mortality in PMV patients, 3,28,32 COPD diagnosis in our study was confirmed by a pulmonary function test in the majority of cases.

There has been an increasing recognition of PMV patients as a subgroup of ICU patients with high-level care needs, and an effort has been made to try to identify predictors of outcome. The scrutiny has focused on factors associated with baseline severity of illness and factors present on hospital discharge. A recently reported prognostic model based on variables associated with a severity of illness at day 21 of mechanical ventilation (use of vasopressors, hemodialysis, platelet count $\leq 150 \times 10^{9} / \mathrm{L}$, and age $\geq 50 \mathrm{y}$ ) proved to be an efficient tool for predicting 1 -year outcome. This could be due to the fact that their proposed variables ${ }^{28}$ reflect the severity of acute critical illness, as most of the non-survivors die in the first few months of follow-up, and death of those patients could be related to unresolved medical issues in the course of their critical illness. Severity of illness on admission and premorbid functional status are associated with worse shortterm mortality, whereas age and comorbidities assessed with the Charlson comorbidity score reflect negatively against long-term survival. ${ }^{7,32}$ The fact that a new respiratory failure was responsible for the death of only $30 \%$ of the patients who died after hospital discharge probably reflects additional comorbidities. Several studies have found more favorable outcome in trauma patients and patients with neuromuscular diseases. $7,30,36,39$

One of the major limitations of this study is associated with difficulties inherent to the small number of patients and its retrospective nature. The study was conducted in a single tertiary-care center, and the results may not generalize to other settings. The variables at hospital discharge, such as presence of neuromuscular weakness or neurocognitive dysfunction following ICU discharge, could not be evaluated. The small number of patients requires caution when interpreting the results. Another limitation is that we used tracheostomy to detect patients who required PMV, which excluded patients who did not undergo tracheostomy because of high severity of illness and poor prognosis.

\section{Conclusions}

A considerable number of critically ill Olmsted county residents underwent tracheostomy for PMV. In addition to previously established predictors of long-term survival (age and severity of illness), the chronic conditions that related to underlying cause of mechanical ventilation (ie, COPD, neuromuscular disease, trauma) should be taken into account when assessing possible outcomes.

\section{REFERENCES}

1. Carson SS. Outcomes of prolonged mechanical ventilation. Curr Opin Crit Care 2006;12(5):405-411.

2. Cox CE, Carson SS, Holmes GM, Howard A, Carey TS. Increase in tracheostomy for prolonged mechanical ventilation in North Carolina, 1993-2002. Crit Care Med 2004;32(11):2219-2226.

3. Engoren M, Arslanian-Engoren C, Fenn-Buderer N. Hospital and long-term outcome after tracheostomy for respiratory failure. Chest 2004;125(1):220-227.

4. Engoren MC, Arslanian-Engoren CM. Outcome after tracheostomy for respiratory failure in the elderly. J Intensive Care Med 2005; 20(2):104-110.

5. Spicher JE, White DP. Outcome and function following prolonged mechanical ventilation. Arch Intern Med 1987;147(3):421-425.

6. Gracey DR, Hardy DC, Koenig GE. The chronic ventilator-dependent unit: a lower-cost alternative to intensive care. Mayo Clin Proc 2000; 75(5):445-449.

7. Chelluri L, Im KA, Belle SH, Schulz R, Rotondi AJ, Donahoe MP, et al. Long-term mortality and quality of life after prolonged mechanical ventilation. Crit Care Med 2004;32(1):61-69.

8. Scheinhorn DJ, Hassenpflug MS, Votto JJ, Chao DC, Epstein SK, Doig GS, Knight EB, Petrak RA. Post-ICU mechanical ventilation at 23 long-term care hospitals: a multicenter outcomes study. Chest 2007;131(1):85-93.

9. Wagner DP. Economics of prolonged mechanical ventilation. Am Rev Respir Dis 1989;140(2 Pt 2):S14-S18.

10. Cox CE, Carson SS, Govert JA, Chelluri L, Sanders GD. An economic evaluation of prolonged mechanical ventilation. Crit Care Med 2007;35(8):1918-1927.

11. Seferian EG, Afessa B, Gajic O, Keegan MT, Hubmayr RD. Comparison of community and referral intensive care unit patients in a tertiary medical center: evidence for referral bias in the critically ill. Crit Care Med 2008;36(10):2779-2786.

12. Rana S, Pendem S, Pogodzinski MS, Hubmayr RD, Gajic O. Tracheostomy in critically ill patients. Mayo Clin Proc 2005;80(12): 1632-1638.

13. Seferian EG, Afessa B. Demographic and clinical variation of adult intensive care unit utilization from a geographically defined population. Crit Care Med 2006;34(8):2113-2119.

14. Klein RJ, Schoenborn CA. Age adjustment using the 2000 projected US population. Healthy People 2010 Stat Notes 2001;20(1):1-10.

15. Knaus WA, Wagner DP, Draper EA, Zimmerman JE, Bergner M, Bastos PG, et al. The APACHE III prognostic system. Risk predic- 


\section{Long-Term Survival in Patients With Tracheostomy and Prolonged Ventilation}

tion of hospital mortality for critically ill hospitalized adults. Chest 1991;100(6):1619-1636.

16. Pauwels RA, Buist AS, Calverley PM, Jenkins CR, Hurd SS. Global strategy for the diagnosis, management, and prevention of chronic obstructive pulmonary disease. NHLBI/WHO Global Initiative for Chronic Obstructive Lung Disease (GOLD) Workshop summary. Am J Respir Crit Care Med 2001;163(5):1256-1276.

17. Puavilai G, Chanprasertyotin S, Sriphrapradaeng A. Diagnostic criteria for diabetes mellitus and other categories of glucose intolerance: 1997 criteria by the Expert Committee on the Diagnosis and Classification of Diabetes Mellitus (ADA), 1998 WHO consultation criteria, and 1985 WHO criteria. World Health Organization. Diabetes Res Clin Pract 1999;44(1):21-26.

18. Derdak S. Acute respiratory distress syndrome in trauma patients. J Trauma 2007;62(6 Suppl):S58.

19. Perrin C, Unterborn JN, Ambrosio CD, Hill NS. Pulmonary complications of chronic neuromuscular diseases and their management. Muscle Nerve 2004;29(1):5-27.

20. Arozullah AM, Daley J, Henderson WG, Khuri SF. Multifactorial risk index for predicting postoperative respiratory failure in men after major noncardiac surgery. The National Veterans Administration Surgical Quality Improvement Program. Ann Surg 2000;232(2): 242-253.

21. Charlson ME, Pompei P, Ales KL, MacKenzie CR. A new method of classifying prognostic comorbidity in longitudinal studies: development and validation. J Chronic Dis 1987;40(5):373-383.

22. Bernard GR, Artigas A, Brigham KL, Carlet J, Falke K, Hudson L, et al. The American-European Consensus Conference on ARDS. Definitions, mechanisms, relevant outcomes, and clinical trial coordination. Am J Respir Crit Care Med 1994;149(3 Pt 1):818-824.

23. Antonelli M, Levy M, Andrews PJ, Chastre J, Hudson LD, Manthous $\mathrm{C}$, et al. Hemodynamic monitoring in shock and implications for management. International Consensus Conference, Paris, France, 27-28 April 2006. Intensive Care Med 2007;33(4):575-590.

24. Combes A, Costa MA, Trouillet JL, Baudot J, Mokhtari M, Gibert C, Chastre J. Morbidity, mortality, and quality-of-life outcomes of patients requiring $\geq 14$ days of mechanical ventilation. Crit Care Med 2003;31(5):1373-1381.

25. Douglas SL, Daly BJ, Gordon N, Brennan PF. Survival and quality of life: short-term versus long-term ventilator patients. Crit Care Med 2002;30(12):2655-2662.

26. Gracey DR, Naessens JM, Krishan I, Marsh HM. Hospital and posthospital survival in patients mechanically ventilated for more than 29 days. Chest 1992;101(1):211-214.
27. Cox CE, Carson SS, Lindquist JH, Olsen MK, Govert JA, Chelluri L. Differences in one-year health outcomes and resource utilization by definition of prolonged mechanical ventilation: a prospective cohort study. Crit Care 2007;11(1):R9.

28. Carson SS, Garrett J, Hanson LC, Lanier J, Govert J, Brake MC, Landucci DL, Cox CE, Carey TS. A prognostic model for one-year mortality in patients requiring prolonged mechanical ventilation. Crit Care Med 2008;36(7):2061-2069.

29. MacIntyre NR, Epstein SK, Carson S, Scheinhorn D, Christopher K, Muldoon S. Management of patients requiring prolonged mechanical ventilation: report of a NAMDRC consensus conference. Chest 2005; 128(6):3937-3954.

30. Pilcher DV, Bailey MJ, Treacher DF, Hamid S, Williams AJ, Davidson AC. Outcomes, cost and long term survival of patients referred to a regional weaning centre. Thorax 2005;60(3):187-192.

31. Bigatello LM, Stelfox HT, Berra L, Schmidt U, Gettings EM. Outcome of patients undergoing prolonged mechanical ventilation after critical illness. Crit Care Med 2007;35(11):2491-2497.

32. Aboussouan LS, Lattin CD, Kline JL. Determinants of long-term mortality after prolonged mechanical ventilation. Lung 2008;186(5): 299-306.

33. Ai-Ping C, Lee KH, Lim TK. In-hospital and 5-year mortality of patients treated in the ICU for acute exacerbation of COPD: a retrospective study. Chest 2005;128(2):518-524.

34. Boles JM, Bion J, Connors A, Herridge M, Marsh B, Melot C, et al. Weaning from mechanical ventilation. Eur Respir J 2007;29(5): 10331056.

35. Scheinhorn DJ, Hassenpflug MS, Votto JJ, Chao DC, Epstein SK, Doig GS, et al. Ventilator-dependent survivors of catastrophic illness transferred to 23 long-term care hospitals for weaning from prolonged mechanical ventilation. Chest 2007;131(1):76-84.

36. Schonhofer B, Euteneuer S, Nava S, Suchi S, Kohler D. Survival of mechanically ventilated patients admitted to a specialised weaning centre. Intensive Care Med 2002;28(7):908-916.

37. Marchese S, Lo Coco D, Lo Coco A. Outcome and attitudes toward home tracheostomy ventilation of consecutive patients: a 10-year experience. Respir Med 2008;102(3):430-436.

38. Sethi JM, Siegel MD. Mechanical ventilation in chronic obstructive lung disease. Clin Chest Med 2000;21(4):799-818.

39. Engoren M, Arslanian-Engoren C. Hospital and long-term outcome of trauma patients with tracheostomy for respiratory failure. Am Surg 2005;71(2):123-127.

This article is approved for Continuing Respiratory Care Education credit. For information and to obtain your CRCE

(free to AARC members) visit

www.RCJournal.com

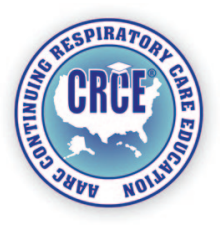

